\title{
Diagnóstico por imágenes de cáncer de mamas. Comparación entre técnica ecográfica y mamografía
}

\section{Diagnosis for images of breast cancer. Comparison between ecographic and mammography}

\section{Diagnóstico por imagem do câncer de mama. Comparação entre ultra-sonografia e mamografia}

\author{
María E. Villavicencio-Romero ${ }^{\mathrm{I}}$ \\ mevr91@,hotmail.com \\ Gregorio A. Moreno-Daza II \\ drmorenoneuro@hotmail.com \\ Gabriel E. Ordóñez-Andrade \\ wolfgabo_5@hotmail.com \\ Lorena M. Paredes Colcha IV \\ lorepc28@hotmail.com
}

Recibido: 17 de mayo de 2019 * Corregido: 15 de junio de 2019* Aceptado: 05 de julio de 2019

\footnotetext{
Médico Cirujano, Universidad Laica Eloy Alfaro De Manabí, Manabí, Ecuador.

Médico, Universidad Laica Eloy Alfaro De Manabí, Manabí, Ecuador.

III. Médico, Universidad Laica Eloy Alfaro De Manabí, Manabí, Ecuador.

Iv. Médico, Universidad Laica Eloy Alfaro De Manabí, Manabí, Ecuador.
} 


\title{
Resumen
}

El cáncer de mama es un problema de salud mundial y la principal causa de muerte entre las mujeres a nivel internacional. En el $96 \%$ de los casos, el cáncer de mama de tipo tratables si se detectan temprano. Si bien las medidas como el autoexamen pueden alertar sobre la presencia de tumores, generalmente para cuando son palpables ya tienen un tamaño considerable. Las estadísticas indican que el $52 \%$ de las mujeres afectadas acuden al hospital en etapas tempranas, esto aumenta la probabilidad de salvar su vida. El cáncer de mama se distingue de otros tipos de cáncer por el hecho de que se produce en un órgano visible y se detecta y se trata en una etapa temprana. Las bajas tasas de supervivencia en los países menos desarrollados pueden ser atribuidas a la falta de detección temprana, así como el diagnóstico inadecuado y las instalaciones de tratamiento. Entre las técnicas diagnósticas implementadas, se encuentra la mamografía utilizada con el fin de buscar o identificar en el seno de la mujer: nódulos, calcificaciones, asimetrías, desestructuración, cambios en la piel y axila. Su uso se basa en un comprensor, rangos de Kv bajos de 25, 28 a 35 (dependiendo), con ayuda de mono emulsión, observadas en una sola pantalla. Por su parte, el eco mamario se basa en un método digital que tiene 15 detectores q transforman los rayos $\mathrm{x}$ en señales eléctricas, el proceso de revelado es distinto a la convencional, no se utiliza químicos es mediante una impresora láser; en las dos se utilizan la misma técnica y el mismo equipo, solo que en la convencional el proceso de revelado se usa químicos y agua. La mamografía como método de diagnóstico presuntivo consiste en tomar imágenes comprimiendo el seno en sentido horizontal y luego oblicuo, con un equipo de rayos $\mathrm{X}$, que usa pequeñas dosis de radiación, ofreciendo imágenes de alta calidad; en cambio, el eco mamario se basa en un método digital que tiene 15 detectores q transforman los rayos $\mathrm{x}$ en señales eléctrica.

Palabras claves: Cáncer de Mamas; eco mamario; mamografía; métodos diagnósticos digitales; imagenología.

\begin{abstract}
Breast cancer is a global health problem and the leading cause of death among women internationally. In $96 \%$ of cases, treatable breast cancer is detected early. While measures such as self-examination can alert you to the presence of tumors, usually by the time they are palpable they already have a considerable size. Statistics indicate that $52 \%$ of affected women go to the hospital early, this increases the probability of saving their lives. Breast cancer is distinguished from other types of cancer by the fact that it occurs in a visible organ and is detected and treated at an early stage. Low survival rates in less developed countries can be attributed to lack of early detection, as well as inadequate diagnosis and treatment facilities. Among the diagnostic techniques implemented, is the mammogram used in order to search or identify in the woman's breast: nodules, calcifications, asymmetries, destructuring, changes in the skin and armpit. Its use is based on a
\end{abstract}

648 Vol. 5, núm. 3, julio 2019, pp. 647-678

María E. Villavicencio-Romero; Gregorio A. Moreno-Daza; Gabriel E. Ordóñez-Andrade; Lorena M. Paredes-Colcha 
compressor, low $\mathrm{Kv}$ ranges from 25, 28 to 35 (depending), with the help of mono emulsion, observed on a single screen. For its part, the breast echo is based on a digital method that has 15 detectors that transform $x$-rays into electrical signals, the development process is different from the conventional one, no chemicals are used is by means of a laser printer; in both the same technique and the same equipment are used, only that in the conventional one the development process uses chemicals and water. Mammography as a method of presumptive diagnosis consists of taking images compressing the breast horizontally and then obliquely, with an X-ray device, which uses small doses of radiation, offering high quality images; instead, the breast echo is based on a digital method that has 15 detectors that transform x-rays into electrical signals.

Key words: Breast Cancer; breast Echo; mammography; digital diagnostic methods; imaging.

\section{Resumo}

O câncer de mama é um problema de saúde global e a principal causa de morte entre as mulheres internacionalmente. Em 96\% dos casos, o câncer de mama tratável é detectado precocemente. Enquanto medidas como o auto-exame podem alertá-lo para a presença de tumores, geralmente no momento em que são palpáveis, elas já têm um tamanho considerável. As estatísticas indicam que $52 \%$ das mulheres afetadas vão ao hospital cedo, aumentando a probabilidade de salvar suas vidas. O câncer de mama é diferenciado de outros tipos de câncer pelo fato de ocorrer em um órgão visível e ser detectado e tratado em um estágio inicial. As baixas taxas de sobrevida nos países menos desenvolvidos podem ser atribuídas à falta de detecção precoce, bem como a instalações inadequadas de diagnóstico e tratamento. Entre as técnicas diagnósticas implementadas, está a mamografia utilizada para buscar ou identificar na mama da mulher: nódulos, calcificações, assimetrias, desestruturação, alterações na pele e na axila. Seu uso é baseado em um compressor, baixo $\mathrm{Kv}$ varia de 25, 28 a 35 (dependendo), com a ajuda de emulsão mono, observada em uma única tela. Por seu turno, o eco da mama é baseado em um método digital que tem 15 detectores que transformam raios- $x$ em sinais elétricos, o processo de desenvolvimento é diferente do convencional, nenhum produto químico é usado por meio de uma impressora a laser; tanto na mesma técnica como no mesmo equipamento, somente no convencional o processo de desenvolvimento usa produtos químicos e água. A mamografia como método de diagnóstico presuntivo consiste em tirar imagens comprimindo a mama horizontalmente e depois obliquamente, com um aparelho de raios $X$, que usa pequenas doses de radiação, oferecendo imagens de alta qualidade; Em vez disso, o eco da mama é baseado em um método digital que possui 15 detectores que transformam os raios $\mathrm{X}$ em sinais elétricos.

Palavras-chave: Câncer de Mama; eco do peito; mamografia; métodos diagnósticos digitais; Imaging

\footnotetext{
649 Vol. 5, núm. 3, julio 2019, pp. 647-678 María E. Villavicencio-Romero; Gregorio A. Moreno-Daza; Gabriel E. Ordóñez-Andrade; Lorena M. Paredes-Colcha
} 


\section{Introducción.}

En los últimos años, la incidencia del cáncer de mama ha ido en aumento, sobre todo en las mujeres en la edad media de su vida. Como respuesta de esto, la epidemiología de esta enfermedad va en rápido crecimiento, lo que ha sido demostrado, a través de estadísticas emanadas por la Organización Mundial de la Salud OMS, la cual refleja que, en países latinoamericanos el incremento medio de mujeres con este tipo de patología fue de $67,5 \%$.

En efecto, el cáncer de mama a nivel mundial representa una de las principales causas de muerte en mujeres de raza blanca, a partir de los 35 años de edad. En el 2015 murieron 410,712 mujeres a causa del cáncer de mama a nivel mundial. Se estima que más de 521.0001 mujeres mueren producto de esta enfermedad cada año en todo el mundo, y en la mayoría de estas pacientes fallecidas la enfermedad no es detectada a tiempo. Organización Panamericana de Salud (OPS, 2016).

Dicho de esta forma, el cáncer de mama es una enfermedad neoplásica con transformación de células que proliferan de manera anormal e incontrolada, ocasionando un crecimiento anormal de zonas de la mama, secreciones, edemas, ulcera miento, enrojecimiento. Según la organización mundial de la salud (OMS, 2017) el cáncer de mama "es una de las principales causas de muerte en países latinoamericanos”. (p.11), lo que lleva a considerar que la mayoría de estas víctimas que mueren por esta enfermedad, fue debido a la falta de un diagnóstico a tiempo y de un buen autoexamen o autoexploración en el seno.

El principal método de diagnóstico del cáncer de mama es la mamografía, el cual consiste en tomar imágenes comprimiendo el seno en sentido horizontal y luego oblicuo, con un equipo de 
rayos $\mathrm{x}$, que usa pequeñas dosis de radiación, ofreciendo imágenes de alta calidad, y hoy en día es el método más efectivo realizado en mujeres de 35 años en adelante, para obtener un diagnóstico presuntivo de esta enfermedad.

Entre sus síntomas más comunes detectables en el 90\% de los pacientes con cáncer de mama, lo representa la presencia de una masa típica, la cual suele ser solitaria, unilateral, sólida, dura, irregular, fija y no dolorosa. Del mismo modo, se encuentran las descargas espontáneas por el pezón, éstas son dadas, a través de un conducto mamario es el segundo signo más frecuente del cáncer de mama. Tal descarga se produce en aproximadamente el 3\% de las mujeres con cáncer de mama, pero el $90 \%$ de los casos de descarga por el pezón traducen patología benigna. (Herrán, 2015).

\section{Figura $\mathbf{N}^{\circ} 1$. Anatomía de la Mama Femenina.}

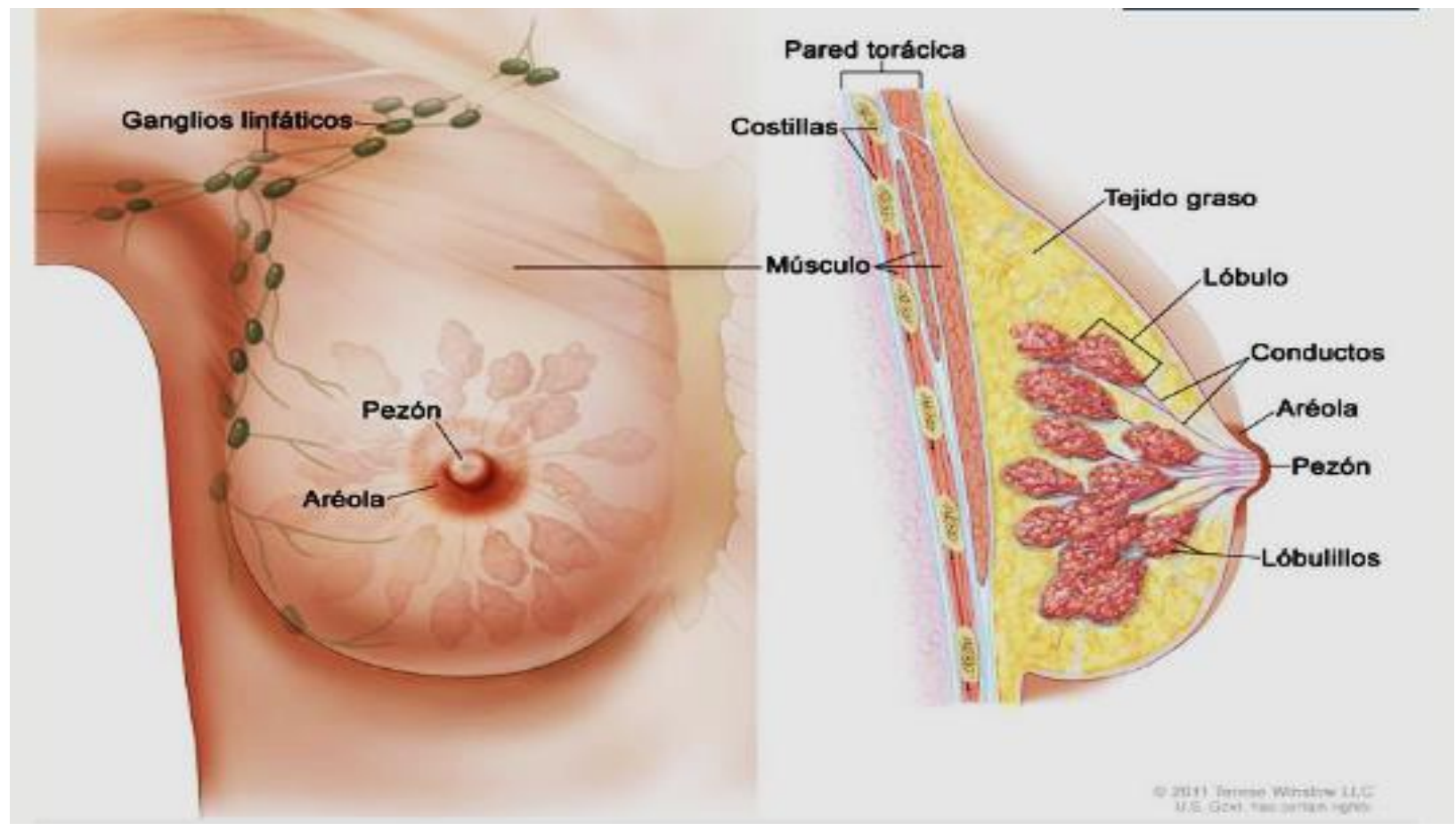

Fuente: Herrán (2015). 
Tales señalamientos llevan a establecer que existen diferentes patologías del seno, las cuales, a través de un diagnóstico preciso logran precisar o identificar la presencia de cáncer, o de alguna anomalía de cuidado, las cuales son muy frecuentes en la mujer a nivel mundial; planteamiento éste que permite determinar la importancia que tienen los estudios de diagnóstico de mamas, entendido como un examen adecuado para detectar cualquier anomalía a tiempo, considerándose que, no sólo pueden encontrase lesiones cancerígenas, sino que pueden diagnosticarse lesiones benignas frecuentes como los quistes de mama, fibroadenomas, dilatación de ductos galactóforos, calcificaciones gruesas conocidas como "palomitas de maíz”, etc.

En este orden, se presenta la mamografía interpretada como una de las técnicas más utilizadas para la detección del cáncer. Este estudio permite encontrar tumores que son muy pequeños al tacto. También, a veces, permite encontrar un carcinoma ductal in situ (CDIS). En el CDIS, las células anormales revisten el conducto de la mama, y en algunas mujeres se puede convertir en cáncer invasivo. En ocasiones, es más difícil de encontrar un tumor cuando el tejido de la mama es denso debido a que los tumores y el tejido denso de la mama se ven blancos en un mamograma. El tejido de las mamas de las mujeres más jóvenes suele ser denso. 


\section{Figura $\mathrm{N}^{\circ}$ 2. Estudio de Mamografía}

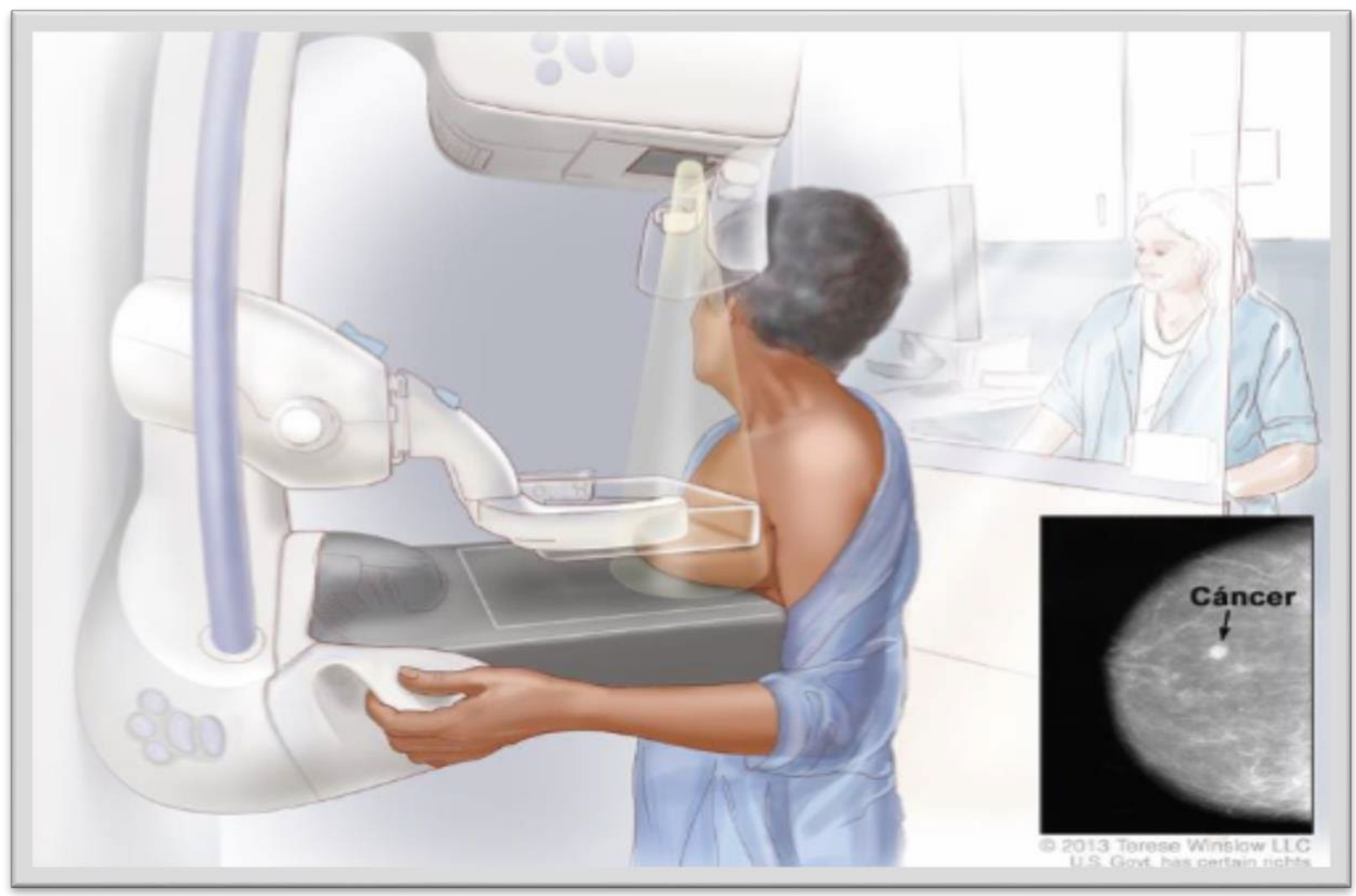

Fuente: Herrán (2015).

En términos generales, la mamografía es un tipo de imagen médica especializada que utiliza un sistema de dosis baja de rayos X para visualizar el interior de las mamas. Dicho de esta forma, un examen de mamografía, llamado mamograma, ayuda en la detección temprana y el diagnóstico de las enfermedades mamarias en las mujeres. No obstante, las imágenes obtenidas por mamografía de exploración a menudo no son suficientes por sí mismas para determinar con certeza si la anormalidad es benigna o maligna.

De la misma forma, se plantea la técnica del eco mamario o ecografía mamaria, conocida por muchos como: ultrasonido mamario, el mismo representa un tipo de tecnología de toma de imágenes que utiliza ondas sonoras para crear fotografías del interior de los senos. El ultrasonido de los senos 
puede capturar imágenes de áreas de estos órganos que podrían ser difíciles de visualizar con una mamografía. También, puede ayudar a determinar si un bulto en el seno consiste en una masa sólida o un quiste lleno de líquido.

En unión de ello, se considera importante resaltar que en el ultrasonido de senos, representa una técnica en donde la persona debe acostarse boca arriba, con el fin de brindar mayor disponibilidad al especialista de capturar las imágenes, lo que posteriormente, le permitirá al ecografista (tecnólogo de ultrasonido) o el radiólogo presionar el transductor con firmeza contra la piel, desplazándolo sobre el seno, obteniendo imágenes que le permiten establecer un diagnóstico. Tales señalamientos, llevan a describir los beneficios que brinda, tanto la mamografía como la ecografía mamaria, como técnicas de diagnóstico preventivo del cáncer de mamas, lo cual será realizado, a través del "análisis del diagnóstico de cáncer de mamas y la comparación entre técnica ecográfica y mamografía.

\section{Tipo de Investigación}

Dentro de toda práctica investigativa, se precisan acciones de carácter metodológico mediante las cuales, se logra conocer y proyectar los eventos posibles que la determinan, así como las características que hacen del acto científico un proceso interactivo ajustado a una realidad posible de ser interpretada. En este sentido, se puede decir, que la presente investigación corresponde al tipo documental, definido por (Dávila, 2012), "se ocupa del estudio de problemas planteados a nivel teórico, la información requerida para abordarlos se encuentra básicamente en materiales impresos, audiovisuales y /o electrónicos”. (p.41). 
En consideración a esta definición, la orientación metodológica permitió la oportunidad de cumplir con una serie de actividades inherentes a la revisión y lectura de diversos documentos donde se encontraron ideas explicitas relacionadas con los tópicos encargados de identificar a cada característica insertada en el estudio. Por lo tanto, se realizaron continuas interpretaciones con el claro propósito de revisar aquellas apreciaciones o investigaciones propuestas por diferentes investigadores, para luego dar la respectiva argumentación a los planteamientos, en función a las necesidades encontradas en la indagación.

\section{Fuentes Documentales}

El análisis correspondiente a las características que predomina en el tema seleccionado, llevan a incluir diferentes fuentes documentales encargadas de darle el respectivo apoyo y en ese sentido cumplir con la valoración de los hechos a fin de generar nuevos criterios que sirven de referencia a otros procesos investigativos. Para (Arias, 2010), las fuentes documentales incorporadas en la investigación documental o bibliográfica, "representa la suma de materiales sistemáticos que son revisados en forma rigurosa y profunda para llegar a un análisis del fenómeno". (p.41). Por lo tanto, se procedió a cumplir con la realización de una lectura previa determinada por encontrar aquellos aspectos estrechamente vinculados con el análisis del "Diagnóstico por imágenes de cáncer de mamas. Comparación entre técnica ecográficay mamografía" para luego explicar mediante un desarrollo las respectivas apreciaciones generales de importancia.

\section{Técnicas para la Recolección de la Información}

La conducción de la investigación para ser realizada en función a las particularidades que determinan a los estudios documentales, tiene como fin el desarrollo de un conjunto de acciones

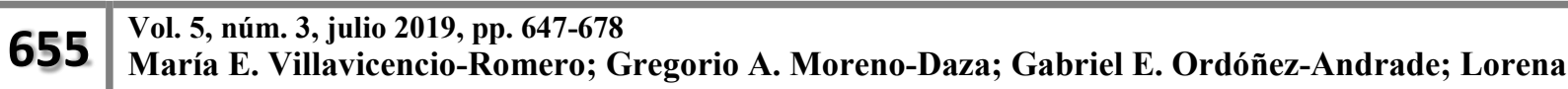
M. Paredes-Colcha
} 
encargadas de llevar a la selección de técnicas estrechamente vinculadas con las características del estudio. En tal sentido, (Arias Ob cit) refiere, que es "una técnica particular para aportar ayuda a los procedimientos de selección de las ideas primarias y secundarias”. (p. 71).

Por ello, se procedió a la utilización del subrayado, resúmenes, fichaje, como parte básica para la revisión y selección de los documentos que presentan el contenido teórico. Es decir, que mediante su aplicación de estas técnicas se pudo llegar a recoger informaciones en cuanto a la revisión bibliográfica de los diversos elementos encargados de orientar el proceso de investigación. Tal como lo expresa, (Arias Ob cit) "las técnicas documentales proporcionan las herramientas esenciales y determinantes para responder a los objetivos formulados y llegar a resultados efectivos" (p. 58). Es decir, para responder con eficiencia a las necesidades investigativas, se introdujeron como técnica de recolección el método inductivo, que hizo posible llevar a cabo una valoración de los hechos de forma particular para llegar a la explicación desde una visión general.

Asimismo, se emplearon las técnicas de análisis de información para la realización de la investigación que fue ejecutada bajo la dinámica de aplicar diversos elementos encargados de determinar el camino a recorrer por el estudio, según, (Arias, Ob cit) las técnicas de procesamiento de datos en los estudios documentales "son las encargadas de ofrecer al investigador la visión o pasos que debe cumplir durante su ejercicio, cada una de ellas debe estar en correspondencia con el nivel a emplear" (p. 123). Esto indica, que para llevar a cabo el procesamiento de los datos obtenidos, es necesario establecer las técnicas que serán seleccionadas, destacándose en este caso, de manera particular: fichas de resumen, textual, registros descriptivos entre otros, los mismos se deben ajustar al nivel que ha sido seleccionado.

\footnotetext{
656 Vol. 5, núm. 3, julio 2019, pp. 647-678

María E. Villavicencio-Romero; Gregorio A. Moreno-Daza; Gabriel E. Ordóñez-Andrade; Lorena 


\section{Resultados}

\section{CÁNCER}

El cáncer es un término que se usa para enfermedades en las que células anormales se dividen sin control y pueden invadir otros tejidos. Las células cancerosas pueden diseminarse a otras partes del cuerpo por el sistema sanguíneo y por el sistema linfático. El cáncer no es solo una enfermedad sino muchas enfermedades. Hay más de 100 diferentes tipos de cáncer. La mayoría de los cánceres toman el nombre del órgano o de las células en donde empiezan; por ejemplo, el cáncer que empieza en el colon se llama cáncer de colon; el cáncer que empieza en las células basales de la piel se llama carcinoma de células basales. (Sett, 2015).

\section{Cáncer de mama.}

El cáncer de mama es la enfermedad maligna no dermatológica más frecuente en las mujeres de todo el mundo. Su incidencia se ha ido incrementando en todos los países occidentales diagnosticándose cada ano a nivel mundial 500.000 casos nuevos (Parra, 2016). En la actualidad puede considerarse un problema sanitario de características epidémicas ya que se estima que 1- 2 mujeres de cada 10 desarrollara cáncer de mama a lo lardo de su vida.

La descripción más antigua del cáncer proviene de Egipto del 1600 A.C. Hipócrates fue un médico griego, que utilizo por primera vez la palabra "los carcinos" y "el carcinoma" para describir tumores de formación. (460- 370 A. C.). Papiro Edwin Smith, fue el que describió 8 casos de tumores que fueron tratados con cauterización con una herramienta llamada horquilla del fuego. (Cleott, 2016). 
Por su parte, Aula Cornelio Celso en el siglo I y galeno en el siglo II refirió la extirpación de los tumores mamarios y el uso cauterio para la cirugía mamaria. Seguidamente, Leónidas de Alejandría fue el médico griego que atribuyo el primer procedimiento quirúrgico para el cáncer de mama "mastectomía". Más adelante, y gracias a estos grandes científicos y muchos años de investigaciones, pudieron realizar un concepto más organizado, y más estructurado de lo que era cáncer de mama.

Según la (OMS 2017), el cáncer de mama “es la transformación de células benignas por células malignas en el proceso de reproducción celular, que crecen de una forma rápida y desordenada ocasionada por la alteración de un gen en la célula madre”. (p.11). Las células alteradas proliferan hasta formar un tumor en forma de masa. Las mismas, pueden llegar a invadir tejidos cercanos y diseminarse a otras partes del cuerpo por medio del torrente sanguíneo y al sistema linfático.

Entre los síntomas que suelen padecer las mujeres con cáncer de mama son las siguientes: asimetría de los senos, piel de los senos arrugada y de color naranja, puede haber secreciones por el pezón, abultamientos en el seno, hoyuelos, un pezón retraído, crecimiento de venas, erosión de la piel del seno. etc. También la paciente puede manifestar dolor en una o en las dos mamas, también al examinarla el médico, pueden palparse lesiones nodulares en los cuadrantes superior externo de cada mama, a nivel retro areolar y a nivel del pezón: carcinoma de Paget.

Según la Organización Mundial de la Salud (OMS 2017) el cáncer de mama no se puede prevenir, sin embargo estudios recientes han demostrado que: 
Se puede reducir el riesgo de sufrir dicha enfermedad realizando ejercicios frecuentemente, evitando el sobrepeso y la obesidad tras la menopausia, eliminar el consumo inapropiado de alcohol, grasa y azucares, ingerir alimentos bajas en grasa como: pescado, vegetales o verduras, hortalizas, ensaladas que tengan tomate, cebolla, comer frutas como guanábana, coco, etc. (p.12).

Lo descrito por el autor permite inferir que, existen diferentes formas, y diversos tratamientos para prevenir esta enfermedad y cómo tratar la misma destacándose entre ellos: la terapia hormonal, quimioterapia, cirugía en este caso hablamos de mastectomía que para entonces en aquel tiempo fue inventada por Leónidas de Alejandría y luego fue modernizada. Existen una serie de investigaciones epidemiológicas, estudios acerca de la distribución y el estado de salud en que se encuentra las personas, se llegó a la conclusión de que dicha patología se da por diferentes factores entre ellas podemos destacar:

Sexo: el cáncer de mama es cien veces más frecuentes en las mujeres que en los hombres (pero es más agresivo en el hombre que en la mujer)

Edad: es un factor importante. Hay un aumento progresivo a partir de los 40 años. Es de destacar el incremento importante de neoplasia de mama en mujeres jóvenes, observado en los últimos años. En nuestro país casi un 17\% de los casos corresponden a mujeres menores de 40 años

Herencia: la mayoría de los autores han demostrado que las pacientes femeninas afectadas de enfermedad maligna de la mama tienen un riesgo dos o tres veces superior a la media de contraer la enfermedad. Son ya clásicos los trabajos de Cady o Anderson, en los que observaron que los riesgos de que se presente cáncer de mama en los familiares de primer grado de una paciente son más elevados. 
Asimismo, se pudo conocer que, entre los hallazgos alcanzados del estudio de esta enfermedad se encuentra que: el factor hereditario a el cáncer de mama, es más frecuente en mujeres blancas que de color. El mismo, parece estar relacionado con los grupos sanguíneos A y O, así como con ciertos grupos de histocompatibilidad como el HL- A7, y es mucho más frecuentes en pacientes con anomalías cromosómicas como la que produce el síndrome de Klinefelter.

Probablemente, los factores hereditarios influyen en lo que se ha llamado mayor receptividad por parte del epitelio glandular mamario de posibles lesiones pre malignas; que pueden aparecer o no dependiendo de factores fenotípicos desencadenantes, tales como enfermedades mamarias previas, caracterizada porque los pacientes que presentan alguna alteración quística o proliferación de sus epitelios mamarios muestran una mayor potencial de malignidad, siendo las lesiones a las que se debe prestar más atención: la adenosis, los quistes papilares, los papilomas intraductales múltiples y las hiperplasias ductales o lobulillares.

De la misma forma, se ha dado a conocer que la menarquía y menopausia constituye un factor que incrementa el riesgo potencial de presentar un carcinoma. Aproximadamente el $40 \%$ de las pacientes diagnosticado de cáncer de mama tuvieron su menopausia por encima de los 52 años. Houven escribió un artículo sobre la administración de estrógeno en la menopausia. La administración repetida de estrógeno durante muchos años aumenta la incidencia del cáncer de mama. (Rester, 2017).

Con igual importancia, estudios han demostrado que los consumidores de contraceptivos hormonales orales están más protegidos frente al padecimiento de lesiones benignas de la mama, por la concentración de progesterona que toman repetidamente o asiduamente. No obstante, el comité asesor de estados unidos sobre fertilidad y salud materna ha destacado recientemente que no se ha 
observado un aumento significativo del desarrollo del cáncer de mama en ningún sub grupo de los usuarios de los contraceptivos orales.

\section{EPIDEMIOLOGIA:}

El cáncer de mama es el tumor maligno más frecuente en la mujer, especialmente en los países occidentales. Existe un incremento progresivo en su incidencia en los últimos años, siendo este aumento más significativo entre las mujeres de menos de 40 años. Aproximadamente, una de cada ocho mujeres será diagnosticada de cáncer de mama a lo largo de su vida y una de cada 30 morirá por esta causa

\section{FACTORES DE RIESGO:}

Se conocen bien varios factores de riesgo del cáncer de mama. Sin embargo en la mayoría de las mujeres afectadas no es posible identificar factores de riesgo específicos, debido a que los antecedentes familiares de cáncer de mama multiplican el riesgo por dos o tres. Sin embargo, existen algunas mutaciones, sobre todo en los genes BRCA1, BRCA2 y p53, que se asocian a un riesgo muy elevado de ese tipo de cáncer. Esas mutaciones son raras y explican solo una pequeña parte de la carga total de cáncer mamario. (Cleott 2016)

De igual manera existen los factores reproductivos asociados a una exposición prolongada a estrógenos endógenos, como una menarquía precoz, una menopausia tardía y una edad madura cuando el primer parto figuran entre los factores de riesgo más importantes del cáncer de mama. Así también, las hormonas exógenas también conllevan un mayor riesgo de cáncer de mama, por lo que las usuarias de anticonceptivos orales y de tratamientos de sustitución hormonal tienen más riesgo

\footnotetext{
661 Vol. 5, núm. 3, julio 2019, pp. 647-678

María E. Villavicencio-Romero; Gregorio A. Moreno-Daza; Gabriel E. Ordóñez-Andrade; Lorena M. Paredes-Colcha
} 
que las mujeres que no usan esos productos. Por su parte, la lactancia materna tiene un efecto protector.

En suma de esto, se observan estudios donde sus autores demuestran que el $21 \%$ de todas las muertes por cáncer de mama registradas en el mundo son atribuibles al consumo de alcohol, el sobrepeso y la obesidad, y la falta de actividad física. Esa proporción fue mayor en los países de ingresos altos (27\%), y el factor más importante fue el sobrepeso y la obesidad. En los países de ingresos bajos y medios, la proporción de cánceres de mama atribuibles a esos factores de riesgo fue del $18 \%$, y la falta de actividad física fue el factor determinante más importante (10\%). (Cere, 2016).

Tabla $N^{\circ}$ 1. Factores de riesgo que inciden en el Cáncer de Mamas en pacientes entre 23 a 65 años, según Informe de la Organización Mundial de la Salud (OMS)

\begin{tabular}{|c|c|c|c|c|}
\hline \multirow[t]{2}{*}{ CARACTERISTICAS INDIVIDUALES } & VALOR & VALOR & MEDIA & MEDIANA \\
\hline & MINIMO & MAXIMO & & \\
\hline EDAD DE LA MUJER CON CA DE MAMA & 23 & 65 & 40 & 37 \\
\hline EDAD INICIO VIDA SEXUAL & 11 & 38 & 18 & 15 \\
\hline EMBARAZOS & 1 & 5 & 2 & 2 \\
\hline EDAD PRIMER PARTO & 15 & 38 & 23 & 22 \\
\hline EDAD ULTIMO PARTO & 17 & 39 & 27 & 26 \\
\hline EDAD LACTANCIA MATERNA & 15 & 38 & 23 & 22 \\
\hline AÑOS USO MAC PILDORAS & 12 & 32 & 18 & 18 \\
\hline AÑOS USO MAC INYECCIONES & 12 & 35 & 19 & 18 \\
\hline N FAMILIAR CON CA MAMA & 1 & 3 & 1 & 2 \\
\hline MENARQUIA & 9 & 15 & 11 & 11 \\
\hline MENOPAUSIA & 38 & 59 & 48 & 50 \\
\hline
\end{tabular}

Fuente: Organización Mundial de la Salud OMS (2017). 
La Tabla descrita, da a conocer las características individuales de la mujer con cáncer de mama, es así que en cuanto a la edad de las mujeres con cáncer de mama, la edad mínima de presentación fue de 23 años, mientras que la máxima de 65 años, con una media de 40 años y una mediana de 37 años de edad, entre los factores encontrados supuestamente de vulnerabilidad están la edad inicio de la vida sexual activa de la cual observamos que las usuarias tenían una edad mínima de 11 años y una máxima de 38 años de edad, mientras que la media fue de 18 y la mediante de 15 años de edad, así mismo la edad del primer parto como mínima fue de 15 y como máximo 38 años, la media de 23 años y la mediana de 22 años.

En tanto a los años de uso de MAC la edad mínima fue de 12 años y la máxima de 32 con una media de 23 y una mediana de 18, en tanto que el uso de MAC inyecciones desde una mínima edad de 12 un máximo de 35 una media de 19 y una mediana de 18, en cuanto al tener familiares con cáncer de mama como mínimo tenían 1 familiar y máximo 3 con una media de 1 una mediana de 2, denotando así que las mujeres con mayor vulnerabilidad a la presentación son aquellas que inician su vida sexual a temprana edad, las que utilizan tempranamente los MAC, las que tienen familiares con cáncer de mama sin embargo es un factor protector las que tienen a una edad media de 23 años su primer parto, coincidiendo con las estadísticas a nivel mundial es así que la OMS nos indica que en cuanto a la edad.

El riesgo de desarrollar cáncer de mama aumenta a medida que la mujer envejece y, en la mayoría de los casos, la enfermedad se desarrolla en mujeres de más de 50 años, en cuanto al antecedente familiar es hereditario si su familia son parientes de primer grado, como madres, hermanas, hermanos e hijos, a quienes se les ha diagnosticado cáncer de mama o de ovarios, en especial antes de los 50 años. Si dos parientes de primer grado desarrollaron cáncer de mama, el 
riesgo es de cinco veces el riesgo promedio, además estudios de genética demuestran que existe un gen que al ser mutado influye en la problemática

Las mutaciones genéticas más frecuentes son mutaciones de los genes 1 y 2 del cáncer de mama se llaman BRCA1 o BRCA2. Las mutaciones de estos genes se vinculan con un aumento del riesgo de desarrollar cáncer de mama y ovario, así como otros tipos de cáncer, en cuanto al embarazo las mujeres que comenzaron a menstruar antes de los 11 o 12 años o llegaron a la menopausia después de los 55 años tienen un mayor riesgo de padecer cáncer de mama porque las células mamarias han estado expuestas al estrógeno y a la progesterona durante un tiempo más prolongado.

Así mismo aquellas que tuvieron su primer embarazo después de los 35 años o las que nunca tuvieron un embarazo a término tienen un mayor riesgo de padecer cáncer de mama. El embarazo puede ayudar a proteger contra el cáncer de mama porque empuja a las células mamarias hacia la última fase de maduración, en tanto que la relación del uso de MAC, en un análisis reciente de datos del Estudio de Salud de Enfermeras, el cual ha estado siguiendo a más de 116000 enfermeras que tenían de 24 a 43 años cuando se inscribieron en el estudio en 1989, encontró que las participantes que usaron anticonceptivos orales tenían un riesgo ligeramente mayor de cáncer de seno. Sin embargo, casi todo el aumento de riesgo se veía entre las mujeres que tomaron un tipo específico de anticonceptivo oral, una píldora "trifásica"

\section{Otros factores de riesgo de consideración son:}

Lactancia materna: está suficientemente comprobado el efecto protector que ejerce la lactancia materna sobre el cáncer de mama. 
Clases sociales Altas: El cáncer de mama afecta con más frecuencia las clases sociales altas, quizás debido a la ingesta de determinado alimentos o al menor número de hijos.

Abuso de alimentos ricos en Colesterol: Existe una posible relación entre esta neoplasia mamaria y el abuso de alimentos ricos en colesterol y azúcar refinada, también las mujeres que han sido excesivamente irradiada deben ser especialmente vigiladas por el riesgo potencial de carcinogénesis.

Aditivos químicos en Alimentos y Otros: Hay otros factores cuya influencia se desconoce por el momento, pero que probablemente pueden desempeñar un papel activo, como son los aditivos químicos de los alimentos, pesticidas, herbicida, etc.

\section{CLASIFICACIÓN DEL CÁNCER DE MAMA.}

Según Oncólogos la Organización Mundial de la Salud O.M.S. (2017), existen diferentes tipos de Cáncer de Mamas, los cuales se clasifican en:

Tumores Malignos de Mama En la mama se agrupan tejidos de diferentes estirpes que pueden dar lugar a diferentes tipos de tumores (sarcomas, basaliomas, linfomas,...); sin embargo sólo trataremos los tumores malignos de mama específicos de esta glándula. Existen otros tumores de tipo benigno que no son el objeto de esta revisión (fibroadenoma, tumor filodes y papiloma intraductal)

Carcinoma no invasivo (in situ)

a) Carcinoma intraductal (o carcinoma ductal in situ): El carcinoma intraductal antaño se consideraba una lesión rara, pero con el aumento del uso de la mamografía que detecta 
lesiones precoces y pequeñas, hoy en día supone aproximadamente del 20 al 30\% de los carcinomas de mama. Está constituido por una población maligna de células que carecen de la capacidad de invadir a través de la membrana basal y que por tanto son incapaces de producir metástasis a distancia. Existen 5 subtipos histológicos: comed carcinoma, sólido, cribiforme, papilar y micro papilar. A excepción del comed carcinoma, estas lesiones son habitualmente ocultas clínicamente y se detectan como hallazgo casual en biopsias de mama o por mamografía. El comed carcinoma se caracteriza por células de alto grado de malignidad en proliferación rápida. Se piensa que fundamentalmente el comed carcinoma, $\mathrm{y}$, con menos probabilidad los subtipos restantes, son precursores del cáncer infiltrante.

b) Carcinoma Lobulillar in situ: Se trata de una lesión histológicamente única que se manifiesta por una proliferación, en uno o más conductos terminales, acinos o ambos a la vez, de células laxamente 18 cohesionadas, a veces algo mayores de lo normal, con raras mitosis y núcleos ovalados o redondos con nucléolos pequeños.

c) Evolución de las lesiones in situ a carcinomas invasivos. El carcinoma intra ductual es un claro precursor del carcinoma invasivo; si bien los pasos iniciales de los caminos que llevan a la tumor génesis mamaria todavía no están definidos, parece que prácticamente todos los cánceres de mama invasivos proceden de un carcinoma intraductual. La presencia de cambios cromosómicos compartidos tanto en el carcinoma intra ductual como en el tejido maligno adyacente invasivo demuestra su relación clonal evolutiva

\section{Tumores invasivos de la Mama}

Carcinoma ductal infiltrante: Es el tipo más frecuente de todos los cánceres mamarios. La mayoría exhibe un llamativo aumento de un estroma denso de tejido fibroso, que da al tumor una 
alta consistencia ("carcinoma escirro"). Histológicamente consiste en células malignas de revestimiento de los conductos dispuestas en cordones, nidos sólidos de células, túmulos, glándulas y masas anastomosadas, o mezclas de estos patrones. Las células invaden claramente el estroma de tejido conectivo. Suele observarse la invasión de espacios peri - vasculares.

Peris neurales, así como de vasos sanguíneos y linfáticos. En función de dos parámetros (grado de atipia nuclear y diferenciación histológica definida por la formación de túbulos), se clasifican en bien diferenciados, moderadamente y pobremente diferenciados (Grado 1- 2-3 respectivamente).

Tabla $\mathbf{N}^{\circ}$ 2. Incidencia en tipos de Cáncer de Mamas en pacientes femeninas latinoamericanas

\begin{tabular}{|l|l|l|}
\hline TIPO DE CANCER EN LA MAMA & TOTAL & $\%$ \\
\hline CANCER DUCTUAL & 113 & 47,5 \\
\hline CANCER LOBULILLAR & 102 & 42,9 \\
\hline CANCER MEDULAR & 15 & 6,3 \\
\hline CARCINOMA MUCINOSO & 4 & 1,7 \\
\hline CARCINOMA PAPILAR & 4 & 1,7 \\
\hline TOTAL & 238 & 100,0 \\
\hline
\end{tabular}

Fuente: Organización Mundial de la Salud OMS (2017) 


\section{Gráfico $N^{\circ} 1$. Porcentaje según tipo de Cáncer de Mamas}

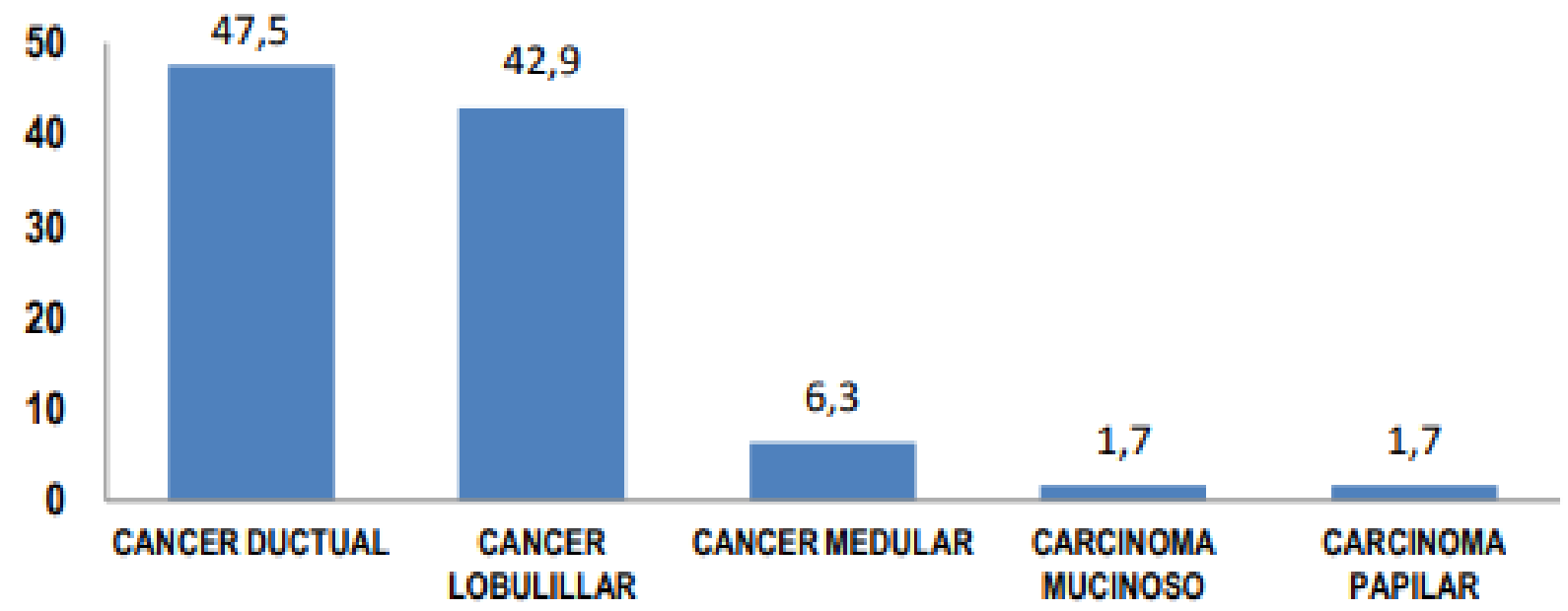

Fuente: Organización Mundial de la Salud OMS (2017).

La Tabla y Gráfico descritos indican el porcentaje de mujeres según el tipo de cáncer de mama, es así que el 47,5\% de mujeres presentaron cáncer ductual, el 42,9\% cáncer lobulillar, y en menor porcentaje el carcinoma minucioso y papilar, coincidiendo los resultados con las estadísticas a nivel mundial ya que la OMS nos indica que el cáncer de mama ductual representa aproximadamente el $80 \%$ de los canceres de seno, siendo la incidencia del 10\% del cáncer lobulillar.

\section{MANIFESTACIONES DEL CÁNCER DE MAMA}

Las manifestaciones más frecuentes del cáncer de mama son los bultos, la secreción del pecho y las alteraciones cutáneas. Pero también existen dos formas especiales, poco frecuentes, de presentación del cáncer de mama: la enfermedad de Paget de la mama y el cáncer inflamatorio de mama. 
Nódulo mamario La presentación clínica más frecuente del cáncer de mama, en tres de cada cuatro ocasiones, es la presencia de un nódulo (bulto) mamario palpable que, por lo general, la misma paciente se descubre de forma casual al ducharse o al vestirse. Sin embargo, más del $75 \%$ de los nódulos mamarios son benignos. Generalmente se trata de un nódulo único, duro, mal definido por palpación y no doloroso. Si se divide la mama en cuatro cuadrantes, tomando como centro el pezón, el cáncer suele localizarse con mayor frecuencia a nivel del cuadrante superior externo.

Secreción del pezón Otra forma de presentación menos frecuente es la secreción del pezón, que de ser sanguinolenta resulta muy sospechosa de cáncer mamario. Raramente se presenta con dolor mamario, siendo indoloro en la gran mayoría de casos.

Alteraciones cutáneas: La presencia de alteraciones cutáneas, como retracción de la piel o del pezón o piel de naranja, se presentan de forma infrecuente y, si se palpa tumoración mamaria por debajo, generalmente indican que la enfermedad ya está muy avanzada.

Presencia de un ganglio palpable en la axila: suele deberse a otra causa, pero siempre hay que buscar una tumoración en la mama vecina. La presencia de ulceraciones cutáneas por invasión de un tumor maligno subyacente hasta la piel es excepcional y significa que se ha llegado a estadios muy avanzados. Eso no debería de ocurrir en modo alguno, pues significa una falta de autocuidado sólo explicable por auto abandono o miedo de la interesada a que se le diagnostique una enfermedad maligna.

La enfermedad de Paget mamaria: Se presenta como una lesión eccematosa y erosionada, enrojecida y húmeda en el pezón y en la aréola, que puede parecer una lesión de la piel sin más importancia si no se conoce esta entidad. Significa la presencia de una infiltración de los 
conductillos galactóforos (los que transportan la leche) cerca del pezón por un cáncer maligno en estadios iniciales, e incluso es posible que se trate de un cáncer in situ antes de ser invasor; de ahí la importancia del reconocimiento precoz de esta entidad.

El cáncer mamario inflamatorio: Es una entidad clínica infrecuente. Se presenta en forma de manchas rojizas que crecen rápidamente hasta juntarse y cubrir gran parte de la mama, junto a un aumento del tamaño de ésta, así como de su consistencia y su temperatura cutánea, todo ello de forma dolorosa. Son tumores que presentan un pronóstico peor al del resto de cánceres de mama.

La detección de tumores malignos de la mama en estadios asintomáticos: incluso antes de ser palpables. Ello es posible gracias a la práctica de mamografías periódicas de rutina, ya sea desde los centros de salud o a través de campañas sanitarias. Obviamente, estos cánceres tienen un pronóstico muchísimo mejor que los que se detectan en estadios sintomáticos.

\section{DIAGNÓSTICO POR IMAGEN}

Los estudios por imagenología representan una herramienta de gran valor para la identificación y prevención del cáncer. Este tipo de estudios representan la posibilidad de obtener el conocimiento de las principales patologías que comprende la glándula mamaria, lo cual es de gran importancia debido a que su identificación conduce a un tratamiento adecuado y da a la paciente la certeza del pronóstico que tanto le interesa, siendo de su interés la evolución histórica de las patologías mamarias tanto de las benignas como de su máxima expresión maligna el cáncer de mama.

Elección del tratamiento: Una vez que se ha confirmado el diagnóstico de cáncer de mama y se han realizado las pruebas necesarias para conocer en qué fase está la enfermedad, se debe 
determinar cuál es el tratamiento más adecuado. En tal caso, el especialista recomendará y explicará las posibilidades del tratamiento más adecuadas en cada caso, para que una vez que la paciente haya recibido la suficiente información pueda, junto con el médico, tomar una decisión. El tratamiento del cáncer de mama, como ocurre en la mayoría de los tumores, es multidisciplinar. Distintas especialidades trabajan juntas para combinar terapias y ofrecer al paciente las mayores posibilidades de curación.

Protocolo o plan terapéutico: En el tratamiento del cáncer de mama se sigue un protocolo, es decir un conjunto de normas y pautas (plan de tratamiento), establecidas en base a la experiencia científica que se tiene en el tratamiento de este tumor. Estos protocolos, que se emplean de forma generalizada en todos los hospitales, recogen las indicaciones o limitaciones del tratamiento en función de los siguientes factores:

- $\quad$ Edad del paciente.

- Estado general.

- Estado hormonal (pre menopausia, menopausia).

- Localización del tumor.

- Fase o estadio en la que se encuentra la enfermedad (TNM).

- Receptores hormonales del tumor.

- Grado de las células.

- Positividad para algunos factores biológicos (por ejemplo Her2)

El diagnóstico por imagen le permitirá al médico tratante tener en cuenta si además del cáncer de mama, existen otras enfermedades importantes que puedan dificultar la realización de

\footnotetext{
671 Vol. 5, núm. 3, julio 2019, pp. 647-678

María E. Villavicencio-Romero; Gregorio A. Moreno-Daza; Gabriel E. Ordóñez-Andrade; Lorena 
algún tratamiento específico. Por tanto, el tratamiento propuesto por el especialista no va a ser el mismo en todos los pacientes. Los tratamientos más frecuentemente empleados en el cáncer de mama son la cirugía, la radioterapia, la quimioterapia y la hormonoterapia.

\section{Detección del Cáncer de Mamas}

1. Examen Mamográfico: Se debería efectuar una mamografía de base a partir de los 35 años, y se debe realizar una por año a partir de los 40 años, en mujeres asintomáticas y sin antecedentes familiares de cáncer de mama. En casos de poseer antecedentes familiares, especialmente si presentaron esta enfermedad antes de los 50 años, los estudios mamográficos deberían comenzar 10 años antes de la edad de presentación de caso en cuestión.

Mientras que no haya suficiente información, la edad límite para sugerir finalizar los controles mamarios, las mamas deben ser evaluadas de manera particular. Puesto que todavía no hay forma de predecir quién desarrollará cáncer de mama y quién no, todas las mujeres deberían ser estimuladas a su evaluación antes que haya cualquier signo o síntoma de la enfermedad. La mamografía debe ser realizada en un mamógrafo de alta definición, en dos incidencias frente y medio lateral oblicuo. También se podrán realizar toma adicional como mamografías magnificadas y focalizadas, y tomas especiales para ver en particular alguna lesión de difícil localización.

Origen de la Mamografía: En 1913, Albert salomón, médico alemán informo en "Archiv Fur Klinisesche chirurgie" sobre la utilidad de los rayos X en las enfermedades mamarias. En 1930 Payr cirujano introduce la mamografía como método de diagnóstico. En 1938, Gershon- Cohen públicó en un tratado el aspecto de la mama en función de la edad y del estado menstrual. En 1951 Leborgne

\footnotetext{
672 Vol. 5, núm. 3, julio 2019, pp. 647-678 María E. Villavicencio-Romero; Gregorio A. Moreno-Daza; Gabriel E. Ordóñez-Andrade; Lorena M. Paredes-Colcha
} 
fue el primero en descubrir depósitos cálcicos en el cáncer de mama. En 1960 Edgar mejora la técnica usando un bajo Kv e introduce la película de alto contraste. En 1967 Gross descubre el molibdeno para su aplicación a la técnica de mamografía, además de introducir la comprensión vigorosa de la mama. En 1969 Lacgr introduce al mercado la primera unidad para mamografía y compresión mamaria.

Gracias a las investigaciones de estos científicos se pudo desarrollar un aparato capaz de detectar diferentes patologías como micro calcificaciones, tumores, quistes, etc. También se logró durante años realizar un concepto más organizado y más estructurado acerca del estudio de mamografía. Según la OMS la mamografía es una radiografía que utiliza una baja dosis de radiación para examinar los senos. El técnico comprime el seno perpendicularmente y después oblicuamente angulando el tubo a 45 grados.

2. Ultrasonido Mamario: O técnica ecográfica, es un estudio complementario a la mamografía. No es un método de screening. El mismo, debe efectuarse guiado por la clínica o la mamografía. Es un método útil para las mujeres pre-menopáusicas con sintomatología mamaria, ideal para evaluar lesiones quísticas, en mujeres embarazadas o en período de lactancia. Deberá realizarse con transductores adecuados para el examen mamario, lineales y de 7,5 mhz o más, y si es posible con el estudio mamográfico disponible para corroborar la imágenes. Es de especial utilidad en mamas mamográficamente densas, complementando y disminuyendo los falsos negativos de la mamografía.

Sus indicaciones más frecuentes son: 
- Mamas o nódulos mamográficos

- Mamas densas con o sin sintomatología clínica.

- Asimetrías y/o imágenes mamográficas no concluyentes (distorsiones o opacidades)

- Masas palpables.

- Procesos inflamatorios.

- Primera evaluación en pacientes menores de 30-35 años.

- Guía de procedimientos intervencionistas.

- Evaluación de las prótesis.

En definitiva, es de gran importancia establecer que las técnicas señaladas representan los medios más utilizados por los especialistas para la detección del cáncer de mamas. A pesar que el objetivo de las mismas se basa en el diagnóstico preventivo de cualquier anomalía estos métodos presentan una serie de diferencias entre las que se encuentran:

\section{Mamografía}

- Emplea una mínima radiación, es decir, es como una radiografía de la mama.

- Es el método más importante para la detección precoz y certera de lesiones cancerosas.

- Muestra signos para el diagnóstico de cáncer de mama en fase microscópica, antes de que alcance un tamaño que pueda ser palpable y detectada en el auto-examen.

- Se realiza por primera vez a los 35 años y luego anualmente.

- Al finalizar el examen, no queda en el cuerpo del paciente ningún tipo de radiación.

- Aporta información que la ecografía no entrega, por ejemplo, la detección y análisis de micro-calcificaciones de sospecha. 
- Su capacidad de detección depende del tamaño del tumor, la densidad del tejido mamario y la habilidad del radiólogo.

\section{Ecografía mamaria}

Es un procedimiento de imagenología que emplea una emisión de ultrasonidos dirigida sobre un cuerpo u objeto como fuente de datos para formar una imagen de los órganos o masas internas con fines de diagnóstico.

No presenta ningún tipo de radiación.

Es el examen recomendado para los pacientes mayores de 35 años de edad para descartar la existencia de lesiones benignas o lesiones sospechosas ocultas dentro del parénquima mamario, y prevenir el cáncer de mama.

$>$ En mayores de 40 años, aumenta la especificidad de la mamografía para la detección del cáncer de mama.

Sirve para caracterizar una lesión. Por ejemplo, ante un nódulo, puede decir si su contenido es sólido (fibroadenoma) o liquido (quiste).

Entrega información que no se puede obtener con la mamografía, como la detección de nódulos en mamas densas, el análisis de las características internas de las tumoraciones y la vascularización de las lesiones, usando Doppler color y otros datos importantes para un diagnóstico diferencial correcto.

Sirve como guía para biopsias o procedimientos invasivos

\footnotetext{
675 Vol. 5, núm. 3, julio 2019, pp. 647-678

María E. Villavicencio-Romero; Gregorio A. Moreno-Daza; Gabriel E. Ordóñez-Andrade; Lorena 


\section{Conclusiones}

El cáncer de mama, representa una de las patologías de mayor incidencia en la mujer. Esta es una de las enfermedades que más ha afectado al género femenino en las últimas décadas. La misma, se basa en el crecimiento desordenado de células del epitelio de la mama, esto lleva al cuerpo a reaccionar de una manera provocando algunos síntomas como: hinchazón de parte o todo el seno (aunque la paciente no sienta una protuberancia definida), irritación o hendiduras en la piel, dolor en el seno o en el pezón, retracción (contracción) de los pezones, enrojecimiento, descamación o engrosamiento de la piel del seno o del pezón, secreción del pezón que no sea leche materna.

Uno de los métodos de diagnóstico más utilizado para su prevención es la ecosonografía, pero el más utilizado y recomendado por la mayoría de los médicos es la mamografía. La mamografía como método de diagnóstico presuntivo consiste en tomar imágenes comprimiendo el seno en sentido horizontal y luego oblicuo, con un equipo de rayos $\mathrm{X}$, que usa pequeñas dosis de radiación, ofreciendo imágenes de alta calidad, y hoy en día es el método más efectivo y realizado en mujeres de 25 años de edad en adelante, para obtener un diagnostico presuntivo de esta enfermedad.

Por otra parte, se encuentra el eco mamario, el cual se basa en un método digital que tiene 15 detectores $\mathrm{q}$ transforman los rayos $\mathrm{x}$ en señales eléctricas, el proceso de revelado es distinto a la convencional, no se utiliza químicos es mediante una impresora láser; en las dos se utilizan la misma técnica y el mismo equipo, solo que en la convencional el proceso de revelado se usa químicos y agua.

\footnotetext{
676 Vol. 5, núm. 3, julio 2019, pp. 647-678

María E. Villavicencio-Romero; Gregorio A. Moreno-Daza; Gabriel E. Ordóñez-Andrade; Lorena 
La mamografía en cambio, es utilizada con el fin de buscar o identificar en el seno de la mujer: nódulos, calcificaciones, asimetrías, desestructuración, cambios en la piel y axila. Las características más importantes que se debe tomar en cuenta de un equipo de mamografía es que: utiliza como método el molibdeno o radio, de la misma forma, usa comprensor, rangos de Kv bajos de 25, 28 a 35 (dependiendo), estableciendo películas mono emulsión, observadas en una sola pantalla.

La mamografía no puede ser en mujeres lactantes, no debe realizarse en pacientes que tenga la menstruación, debe esperar 7 días después de los 5 días de menstruación, debe predominar tres colores en la imagen: NEGRO, BLANCO Y GRIS. Este tipo de estudio no confirma el resultado final de tener cáncer de mama, sino la biopsia, ya que el tejido mamario normal puede ocultar un cáncer, quiste, etc. De allí, la necesidad de realizarse otros estudios adicionales o complementarios como: RMI, biopsia, exámenes clínicos, etc.

La mamografía para mayor veracidad debe ser realizada en un mamógrafo de alta definición, en dos incidencias frente y medio lateral oblicuo. También, se podrán realizar toma adicional como mamografías magnificadas y focalizadas, y tomas especiales para ver en particular alguna lesión de difícil localización. Este estudio debe aplicarse a partir de los 35 años, y se debe realizar una por año a partir de los 40 años, en mujeres asintomáticas y sin antecedentes familiares de cáncer de mama.

Contrario a esto, la ecografía representa un estudio complementario a la mamografía. No es un método de screening. El mismo debe efectuarse guiado por la clínica o la mamografía. Es un método útil para las mujeres pre-menopáusicas con sintomatología mamaria, ideal para evaluar lesiones quísticas, en mujeres embarazadas o en período de lactancia.

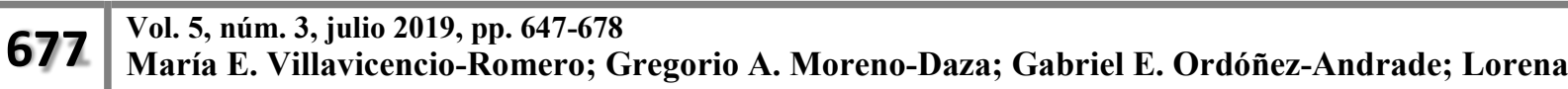
M. Paredes-Colcha
} 
Asimismo, la ecografía deberá realizarse con transductores adecuados para el examen mamario, lineales y de 7,5 mhz o más, y si es posible con el estudio mamográfico disponible para corroborar la imágenes. En términos generales, es de especial utilidad su uso; en especial en mamas mamográficamente densas, ya que permitirá complementar y disminuir los falsos negativos de la mamografía.

\section{Bibliografía.}

Arias, F. (2010). Paradigmas, diseño y enfoque de la Investigación Científica. España: Editorial: Luces.

Cere, D. (2016). Epidemiología del Cáncer de Mamas. Informe Sanitario de Salud Pública de las Naciones Unidas., 32.

Cleott, J. (2016). Cáncer de Mamas. Diagnósticos Preventivos. Revista de Medicina Preventiva de Buenos Aires, Argentina., 13.

Dávila, N. (2012). Paradigmas de la Investigación Científica. Pereire, Colombia: Editorial: Las Brisas.

Herrán, B. (2015). Anatomía de las Mamas. Revista Oncológica de Medicina Médica Familiar., 32.

OMS, O. M. (2017). Prevalencia de cáncer de mamas según diagnósticos ecográficos. Revista Vida y Salud de la Universidad de la Habana en Cuba., 11.

OPS, O. P. (2016). Incidencia de cáncer de mamas en mujeres latinas. Revista de Salud Integral de la Universidad Autónoma de México., 13.

Parra, C. (2016). Oncología referenciada al Cáncer de Mamas. Revista de Anatomía Integral de España., 10.

Rester, C. (2017). Factores de Riesgo en el Cáncer de Mamas. Revista Enfermedades Crónicas y Agudas Universales de la Universidad de la Habana en Cuba, 33., 24.

Sett, A. (2015). Estudios diagnósticos de Cáncer de Mamas. Boletín Informativo Médico Oncológico de IMBIOMED, 25. 